\title{
MicroRNA-29c restores cisplatin sensitivity in liver cancer through direct inhibition of sirtuin 1 expression
}

\author{
WEI ZHANG ${ }^{1}$ and PENG LUO ${ }^{2}$ \\ Departments of ${ }^{1}$ Geriatric Medicine and ${ }^{2}$ Cardiology, Sichuan Academy of Medical Sciences and \\ Sichuan Provincial People's Hospital, Chengdu, Sichuan 610072, P.R. China \\ Received May 7, 2017; Accepted May 17, 2018
}

DOI: $10.3892 / \mathrm{ol} .2018 .8801$

\begin{abstract}
Liver cancer is one of the most prevalent human tumors in the world. Despite recent advances regarding the understanding of the molecular basis of liver cancer and the introduction of novel chemotherapeutic approaches, liver cancer remains associated with a poor prognosis. Sirtuin 1 (SIRT1) was identified to be abnormally upregulated in liver cancer. Dysregulation of microRNAs (miRs/miRNAs) is associated with a variety of types of cancer, and miRNAs may also serve a role in tumorigenesis and progression. The present study demonstrated that following the selection of the cisplatin chemoresistant HepG2 cell line, miR-29c is downregulated using reverse transcription-quantitative polymerase chain reaction. Furthermore, overexpression of miR-29c in cisplatin-resistant cancer cells was demonstrated to inhibit tumor cell proliferation and to promote apoptosis in vitro and in vivo, as well as restoring cisplatin chemosensitivity by using a cell counting assay, colony formation assay, Annexin V-fluorescein isothocyanate/propidium iodide apoptosis analysis, terminal deoxynucleotidyl transferase dUTP nick end labeling and xenograft tumors in nude mice. Mechanistically, according to bioinformatics analysis and a luciferase assay, miR-29c may directly target SIRT1 mRNA and repress SIRT1 expression, which is positively associated with the chemoresistance of liver cancer and may ultimately provide a novel therapeutic method.
\end{abstract}

\section{Introduction}

Liver cancer is one of the most prevalent human tumors worldwide (1) and is ranked as the third leading cause of cancer-associated mortality in China (2). In the majority of

Correspondence to: Dr Peng Luo, Department of Cardiology, Sichuan Academy of Medical Sciences and Sichuan Provincial People's Hospital, 32 West Second Section First Ring Road, Chengdu, Sichuan 610072, P.R. China

E-mail: lancelot.luo@qq.com

Key words: microRNA-29c, sirtuin 1, liver cancer, cisplatin resistance cases, liver cancer develops from chronic inflammation and cirrhosis caused by infections from the hepatitis B and C viruses, ethanol or aflatoxins (3). Despite recent advances in the comprehension of the molecular basis of liver cancer and the use of novel chemotherapeutic approaches, liver cancer remains associated with a poor prognosis (4). This is primarily due to only a limited number of patients being able to undertake potentially curative treatments, including surgical resection followed by orthotopic liver transplantation (5). Furthermore, the mortality rate has declined only modestly, owing to the chemoresistance of liver cancer (4). Therefore, there is an urgent requirement for development of effective therapeutic strategies for patients with liver cancer in the advanced stage of the disease.

The initiation of liver cancer has long been established to be the result of different genetic alterations that ultimately lead to malignant transformations (6). MicroRNAs (miRNAs/miRs) are endogenous, small, non-coding regulatory RNAs that are 22 nucleotides in length (7). miRNAs are able to act as post-transcriptional regulators to negatively regulate the expression of genes by binding directly to the 3'-untranslated regions (3'-UTRs) of target mRNAs in a sequence-specific manner, leading to mRNA degradation (7). Previous studies have demonstrated that miRNA-mediated regulation of gene expression exhibits a role in the development, differentiation, proliferation and apoptosis of cells. The dysregulation of miRNAs is associated with a variety of types of cancer, and miRNAs may also serve a role in tumorigenesis and progression (8-11). miRNA targets include tumor suppressor and oncogenes $(8,9)$, for example, miRNA-449 has been demonstrated to repress the DNA synthesis, mitotic entry and proliferation of liver cancer cells (5). Mechanistically, in hepatoma cells, miR-449 controls lipogenesis and cholesterogenesis by the inhibition of SIRT1 and SREBP-1c expression, and the downregulation of their targeted genes (5).

Sirtuin 1 (SIRT1) can function as either a tumor suppressor or an oncogene during cancer development, and upregulation of SIRT1 is able to suppress colon cancer growth (12). SIRT1 is positively associated with malignancy in other types of cancer (13) and was previously identified to be abnormally upregulated in liver cancer, where it promoted tumor growth (14). Consequently, inhibiting SIRT1 activity alone or in combination with other therapies has been 
suggested as a novel therapeutic strategy for the treatment of liver cancer (15).

The miR-29 family is composed of members with conserved miRNA sequences including miR-29a, miR-29b, miR-29c and miR-29d (16). miR-29c was demonstrated to inhibit cell growth, cell migration and invasion in pancreatic cancer by targeting integrin subunit $\beta 1$ (17). In bladder cancer, miR-29c overexpression inhibited cell growth, suppressed cell migration and resulted in an accumulation of cells in the G1 phase during the cell cycle through the target gene cyclin dependent kinase 6 (18). miR-29c may function as a tumor suppressor serving a crucial role in the development of liver carcinoma by targeting protein phosphatase, $\mathrm{Mg} 2+/ \mathrm{Mn} 2+$ dependent 1D (19). miR-29c is downregulated in gastric cancer tissues and cell lines, and the overexpression of miR-29c inhibits cell proliferation, promotes apoptosis and arrests the cell cycle at the G1/G0 phase by targeting nuclear autoantigenic sperm protein (20).

The present study aimed to uncover the function of miR-29c in chemoresistance and the mechanisms by which miR-29c regulates the cisplatin (cis-diamminedichloroplatinum, CDDP) resistance of liver cancer.

\section{Materials and methods}

Cell culture. The HepG2 cell line was obtained from the American Type Culture Collection (Manassas, VA, USA) and passaged for a period of $<6$ months. The HepG2 cell line was originally assumed to be a hepatocellular carcinoma cell line, but was subsequently identified to originate from a hepatoblastoma, hence the emphasis of the present study on 'liver cancer' (21). The cells were cultured in Dulbecco's modified Eagle's medium (DMEM; Gibco; Thermo Fisher Scientific, Inc., Waltham, MA, USA) containing $10 \%$ fetal bovine serum (Gibco; Thermo Fisher Scientific, Inc.) and $1 \%$ penicillin and streptomycin, at $37^{\circ} \mathrm{C}$ in a humidified $5 \% \mathrm{CO}_{2}$ incubator.

Selection of chemoresistant cell line. CDDP resistant HepG2 cell line (CDDP-R) was derived from original parental cell line (CDDP-S) by continuous exposure to cisplatin (Sigma-Aldrich; Merck KGaA, Darmstadt, Germany) following initial dose-response studies of cisplatin $(0,1.25$, $2.5,5,10 \mu \mathrm{M})$ over $72 \mathrm{~h}$ at $37^{\circ} \mathrm{C}$ from which half maximal inhibitory concentration $\left(\mathrm{IC}_{50}\right)$ values were obtained. Initially, HepG2 was treated with cisplatin $(4.7 \mu \mathrm{M})\left(\mathrm{IC}_{50}\right)$ for $72 \mathrm{~h}$ at $37^{\circ} \mathrm{C}$. The media (DMEM + 10\% FBS, Gibco; Thermo Fisher Scientific, Inc.) was removed and cells were allowed to recover for a further $72 \mathrm{~h}$. This development period was performed for $\sim 6$ months. $\mathrm{IC}_{50}$ concentrations were reassessed. Cells were then maintained continuously in the presence of cisplatin at the new $\mathrm{IC}_{50}$ concentration $(20.5 \mu \mathrm{M})$ at $37^{\circ} \mathrm{C}$ for a further 6 months.

Plasmid construction and extraction. pVax-based SIRT1 overexpression plasmid was purchased from Fulengen Bio Co., Ltd. (Guangzhou, China). The pVax empty plasmid was used as transfection control. All plasmids were transformed into DH5 $\alpha$ cells (Genewiz, Inc., Suzhou, China) for amplification and DNA was extracted by the EndoFree Plasmid kit (Qiagen $\mathrm{GmbH}$, Hilden, Germany), according to the manufacturer's protocol. The concentration was determined by measuring the A260/A280 ratio using a Thermo ND 2,000 spectrophotometer (Thermo Fisher Scientific, Inc.). The plasmid was stored at $-20^{\circ} \mathrm{C}$ until further use. The plasmid transfection was conducted using $2 \mu \mathrm{g}$ plasmid per well using Lipofectamine 3000 (Invitrogen; Thermo Fisher Scientific, Inc.) according to the manufacturer's protocol.

Luciferase assay. The SIRT1-3'UTR containing the miR-29c binding site and the miR-29c mutant binding site were purchased from Genewiz, Inc., and extracted using the EndoFree Plasmid kit (Qiagen GmbH.). The plasmids (2 $\mu \mathrm{g} /$ well) were co-transfected with miR-29c into HepG2 cells using Lipofectamine 3000 (Invitrogen; Thermo Fisher Scientific, Inc.) according to the protocol previously described by Luo et al (22). A luciferase reporter assay (Promega Corporation, Madison, WI, USA) was purchased and used to measure luciferase activity at $4 \mathrm{~h}$ post-transfection, according to the manufacturer's protocol. The relative luciferase activity was normalized to the miR-NC group.

In vitro proliferation and colony formation assay. For proliferation assays, cells were seeded at $2 \times 10^{3}$ cells per well in 96-well plates, as previously described (23). Cell Counting Kit-8 (Dojindo Molecular Technologies, Inc., Shanghai, China) was used and absorbance was measured at $450 \mathrm{~nm}$ for each well at different time points $(0,24,48$ and $72 \mathrm{~h})$ using a microplate reader (Thermo Fisher Scientific, Inc.). For colony formation assays, cells were plated at 500-1,000 cells per well into 6 -well plates and cultured for $\sim 14$ days, followed by crystal violet $(0.5 \% \mathrm{w} / \mathrm{v})$ staining for $30 \mathrm{~min}$ at room temperature, and counted using a light Stereomicroscope (x4).

Reverse transcription-quantitative polymerase chain reaction $(R T-q P C R)$. miRNAs were obtained using the mirVana miRNA Isolation kit according to the manufacturer's protocol (Ambion; Thermo Fisher Scientific, Inc.). RT-qPCR was performed for miR-29c using miRNA primers obtained from Exiqon A/S (Vedbæk, Denmark). $\beta$-actin was used as a loading control. The primers of miR-29c and $\beta$-actin were not supplied according to the rules of the company (Exiqon A/S, Vedbæk, Denmark). First, cDNA was synthesized from all miRNA samples according to the manufacturer's protocol (Exiqon A/S). Synthesized cDNAs were used as templates for gene-expression analysis through RT-qPCR with SYBR Green (Applied Biosystems; Thermo Fisher Scientific, Inc.). The qPCR conditions were as follows: Denaturation at $94^{\circ} \mathrm{C}$ for $2 \mathrm{~min}$, amplification for 30 cycles at $94^{\circ} \mathrm{C}$ for $0.5 \mathrm{~min}$, annealing at $60^{\circ} \mathrm{C}$ for $0.5 \mathrm{~min}$ and extension at $72^{\circ} \mathrm{C}$ for $1 \mathrm{~min}$, followed by a terminal elongation step at $72^{\circ} \mathrm{C}$ for $10 \mathrm{~min}$. Data were analyzed with the $2^{-\Delta \Delta \mathrm{Cq}}$ method (24).

Apoptosis analysis. Cells $\left(2 \times 10^{5}\right)$ transfected with miRNA and treated by CDDP were harvested at $48 \mathrm{~h}$ post-transfection and stained with Annexin V-FITC/PI Apoptosis Detection kit I (BD Pharmingen; BD Biosciences, San Jose, CA, USA). Apoptotic cells were assessed in triplicate and the experiment was repeated three times independently by flow cytometry (FACS Calibur; BD Biosciences) with FACSComp software (version 5.1; BD Biosciences). 
Xenograft tumors in nude mice. CDDP-R cells stably expressing miR-NC or miR-29c $\left(5 \times 10^{6}\right.$ cells in $100 \mu$ l DMEM) were injected subcutaneously into the flanks of Balb/c nude mice (4 mice/group) (5 weeks old, 18-20 g, male; Vital River Laboratories, Beijing, China). Mice were kept in a specific pathogen-free environment, on a $12 \mathrm{~h}$ light/12 h dark cycle at a room temperature of $22 \pm 2^{\circ} \mathrm{C}$ with ad libitum access to food and water. CDDP (20 nmol in $100 \mu \mathrm{l}$ saline) was injected every 3 days (5 times). An equal volume of normal saline was injected as a negative control. Tumor volumes were measured every 5 days. Tumor weights were measured immediately after sacrificing the mice, and tumor samples were harvested for whole protein lysates and embedded in paraffin for sectioning, as previously described by Dai et al (25). Procedures involving animals conformed to the guidelines of the Institutional Animal Care and Use Committee of Sichuan Academy of Medical Sciences and Sichuan Provincial People's Hospital (Sichuan, Chengdu, China) and study approval was obtained.

TUNEL assay. Tumor tissue sections were examined for the presence of apoptotic cells using TUNEL assay, in which fragmented DNA from apoptotic cells is end-labeled with the fluorophore. The biopsy samples were fixed in $10 \%$ phosphate-buffered formalin (Thermo Fisher Scientific, Inc.) for $24 \mathrm{~h}$ at room temperature, processed and then embedded in paraffin. Serial $4-\mu \mathrm{m}$ thick tissue sections were analyzed using the DeadEnd ${ }^{\mathrm{TM}}$ Fluorometric TUNEL system (Promega Corporation) according to the manufacturer's protocol. Following deparaffinization and rehydration, sections were fixed, permeabilized with proteinase $\mathrm{K}$ for 8-10 $\mathrm{min}$, and repeatedly fixed. The sections were then covered with $50 \mathrm{ml}$ terminal deoxynucleotidyl transferase mix for $1 \mathrm{~h}$ at $37^{\circ} \mathrm{C}$ in a humidified chamber. The coverslips were removed and the sections were immersed in 2X SSC buffer for $15 \mathrm{~min}$, washed with PBS and mounted with medium that included DAPI $(1.5 \mu \mathrm{g} / \mathrm{ml})$ (Vectashield ${ }^{\circledR}$; Vector Laboratories Inc., Burlingame, CA, USA) at room temperature $\left(22-25^{\circ} \mathrm{C}\right)$ for $15 \mathrm{~min}$. Fluorescence images of three different fields of view were captured using a fluorescence microscope (Olympus Corporation, Tokyo, Japan).

Western blot analysis. The proteins were extracted with ice-cold lysis buffer containing $1 \mathrm{mM}$ EDTA, $20 \mathrm{mM}$ Tris- $\mathrm{HCl}$ (pH7.5), $1 \mathrm{mM}$ dithiothreitol, $0.1 \mathrm{mM}$ phenylmethylsulfonyl fluoride, $5 \mathrm{mM} \mathrm{MgCl}_{2}$ and a protease inhibitor cocktail (1:100) (Pierce, Thermo Fisher Scientific Inc.), and then centrifuged at $12,000 \mathrm{x} g$ for $20 \mathrm{~min}$ at $4^{\circ} \mathrm{C}$. Protein concentration of the supernatant from the extract was measured with the Bicinchoninic Acid assay kit (Beyotime Institute of Biotechnology, Beijing, China). Equivalent amounts (30 $\mu \mathrm{g})$ of proteins were loaded on $12 \%$ SDS-PAGE and transferred to polyvinylidene difluoride membranes (Merck KGaA). The membranes were blocked in Tris-buffered saline-Tween 20 and probed with anti-SIRT1 at $4^{\circ} \mathrm{C}$ overnight (dilution, 1:1,500; catalog no. ab32441; Abcam, Cambridge, UK). Following washing, the membranes were incubated with horseradish peroxidase-conjugated secondary antibodies (dilution, 1:10,000; cat no. ZB-5301; OriGene Technologies, Inc., Beijing, China) for $60 \mathrm{~min}$ at room temperature. All blots were probed with antibodies against $\beta$-actin at $4^{\circ} \mathrm{C}$ overnight (dilution 1:3,000; cat no. MABT825; Merck KGaA) as a loading control. Immobilon ${ }^{\circledR}$ ECL Ultra Western HRP Substrate (cat no. WBULS0500; EMD Millipore, Billerica, MA, USA) was used for detection with X-ray film. The densitometry was measured by Image J software (Version 1.48; National Institutes of Health, Bethesda, MD, USA).

Bioinformatics analysis. The potential target genes of miR-29c were predicted using three different online programs with databases of different algorithms, including TargetScan (http://www.targetscan.org/), MicroRNA.org (http://www.microrna.org/) and miRDB (http://mirdb.org/) using h-miR-29c as a keyword on the 8th November 2016. The predicted targets were listed.

Statistical analysis. Continuous normally distributed variables are represented graphically as the mean \pm standard deviation. For statistical comparison of quantitative data between groups, analysis of variance (ANOVA) with Dunnett's multiple comparisons or Student's t-test was performed. All statistical analyses were performed using SPSS 22.0 statistical software (IBM Corp., Armonk, NY, USA). P<0.05 was considered to indicate a statistically significant difference.

\section{Results}

miR-29c is downregulated in CDDP-resistant liver cancer cells. To assess the expression of miR-29c in CDDP-R liver cancer, CDDP-R HepG2 cell lines were selected by gradually increasing CDDP concentration in the culture medium. The $\mathrm{IC}_{50}$ value for CDDP in the parent HepG2 CDDP-sensitive (CDDP-S) line and the derived CDDP-resistant HepG2 (CDDP-R) cells was calculated. It was demonstrated that the $\mathrm{IC}_{50}$ value in the CDDP-S cells ( $\left.\mathrm{IC}_{50}, 4.7 \pm 0.4 \mu \mathrm{M}\right)$ (Fig. 1A) was significantly lower than that in the CDDP-R cells $\left(\mathrm{IC}_{50}, 82.2 \pm 3.1 \mu \mathrm{M}\right)(\mathrm{P}<0.05)$ (Fig. 1B). The colony formation abilities of the two cell lines was analyzed, and the CDDP-R cells were demonstrated to exhibit increased colony formation abilities (CDDP-S, $143 \pm 18$ vs. CDDP-R, 264 \pm 25 ; $\mathrm{P}<0.01$ ) (Fig. 1C-D). Notably, miR-29c expression levels, as detected by qPCR, were significantly lower in CDDP-R cells than in CDDP-S cells (CDDP-R, 0.21 \pm 0.05 ; $\mathrm{P}<0.001$ ) (Fig. 1E). These results suggested that miR-29c is downregulated in CDDP-R cancer cells.

Overexpression of miR-29c restores CDDP sensitivity in liver cancer cells in vitro. As miR-29c expression was reduced following acquisition of resistance to CDDP, the present study investigated the role of miR-29c in chemoresistance. A plasmid expressing miR-29c was introduced and it was validated that the plasmid effectively enhanced miR-29c levels in the CDDP-R cells (miR-29c vs. miR-negative control (NC), $14.2 \pm 3.2$ vs. $1.0 \pm 0.02$ ) (Fig. 2A). Overexpression of miR-29c along with CDDP treatment $(20 \mu \mathrm{M})$ in CDDP-R cells resulted in significantly reduced viability compared with that in the untreated group and the miR-NC plus CDDP-treated group (decreased 45.0\%; miR-29c vs. miR-NC, $0.82 \pm 0.13$ vs. $1.49 \pm 0.21$ ) (Fig. 2B). The colony formation assay results corroborated these results; treatment with miR-29c and CDDP $(20 \mu \mathrm{M})$ resulted in reduced colony numbers in CDDP-R 
A

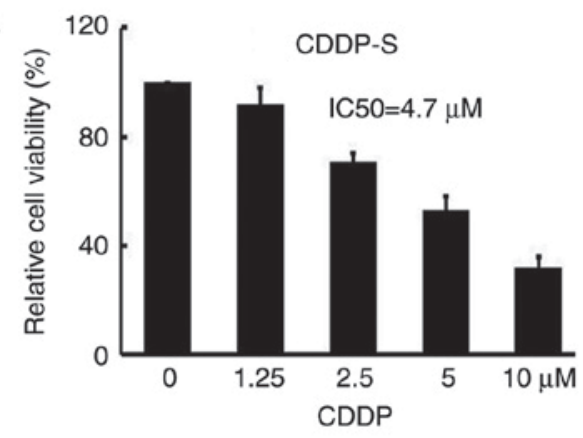

B

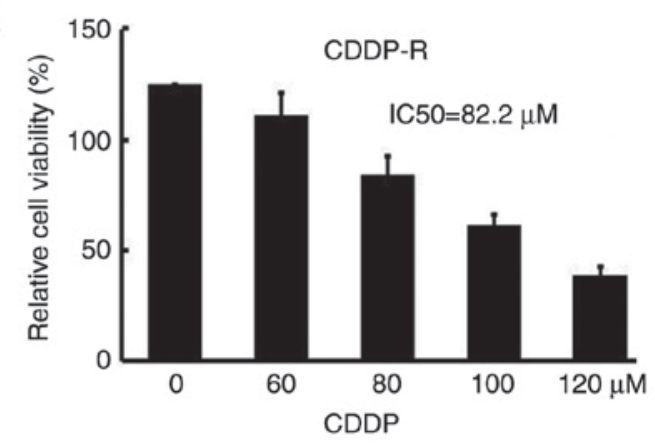

C

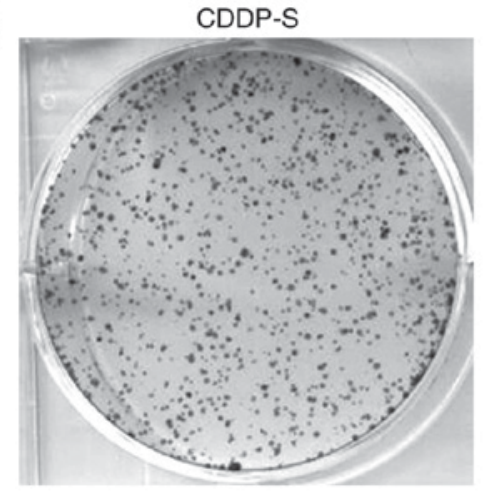

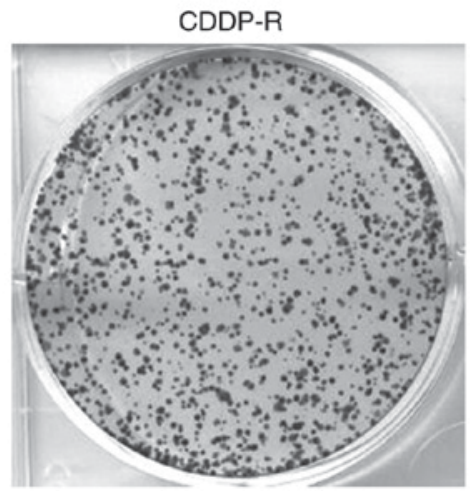

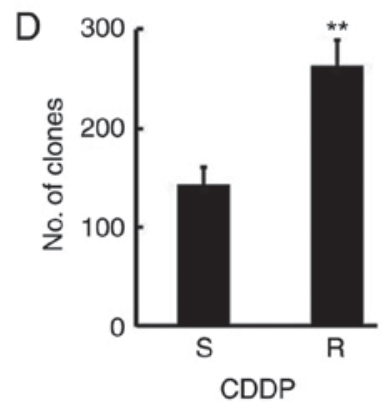

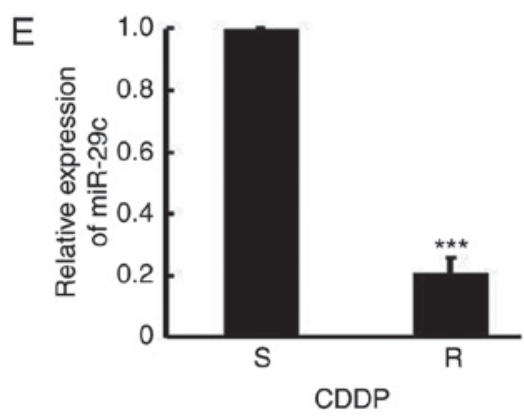

Figure 1. Expression of miR-29c is downregulated in CDDP resistant liver cancer cells. (A) The relative cell viability of the parent CDDP-sensitive HepG2 cell line and the $\mathrm{IC}_{50}$ value for CDDP. (B) The relative cell viability of the selected CDDP-resistant HepG2 cell line and the $\mathrm{IC}_{50}$ value for CDDP. (C) Crystal violet staining of colony formation of CDDP-S and CDDP-R cells after 10 days, with (D) statistical analysis of colony numbers for triplicate experiments $(\mathrm{n}=3)$. (E) Relative miR-29c expression in CDDP-S and CDDP-R cells by quantitative polymerase chain reaction. Data shown are the mean \pm standard deviation of three independent experiments. ${ }^{* *} \mathrm{P}<0.01$ and ${ }^{* * *} \mathrm{P}<0.001$ vs. sensitive group. $\mathrm{CDDP}$, cisplatin; $\mathrm{S}$, sensitive; $\mathrm{R}$, resistant; $\mathrm{IC}_{50}$, half maximal inhibitory concentration; miR, microRNA.

cells (decreased $72.9 \%$; miR-29c vs. miR-NC, $67 \pm 15$ vs. $247 \pm 27 \mathrm{~mm}^{3}$ ) (Fig. 2C and D). Furthermore, an improved rate of apoptosis in CDDP-R cells was observed following treatment with miR-29c and CDDP (increased 8.0 times; miR-29c vs. miR-NC, $21.83 \pm 4.25$ vs. $2.73 \pm 0.72 \%$ ) (Fig. $2 \mathrm{E}$ and F). These results indicate that overexpression of miR-29c could restore the CDDP sensitivity of CDDP-R cells in vitro.

Overexpression of miR -29 c restores $C D D P$ sensitivity in liver cancer in vivo. To validate the observed phenomenon in vivo, a xenograft tumor model in nude mice was established, using the selected CDDP-resistant HepG2 cell line with CDDP treatment and stable expression of either miR-NC or miR-29c. The present study demonstrated that restoring miR-29c in CDDP-R cells markedly reduced xenograft tumor growth, including tumor volume (decreased 55.5\%; miR-29c vs. miR-NC, $428.4 \pm 59.2$ vs. $\left.963.2 \pm 102.3 \mathrm{~mm}^{3}\right)$ and tumor weight (decreased 53.4\%; miR-29c vs. miR-NC, $0.48 \pm 0.09$ vs. $1.03 \pm 0.14 \mathrm{~g}$ ), whereas there was no significant difference between the CDDP + miR-NC and normal saline control groups (Fig. 3A and B). RT-qPCR analysis demonstrated that the expression of miR-29c in the CDDP + miR-29c- treated tumors was 9.42 times higher than that in the control groups (Fig. 3C). TUNEL staining revealed a markedly increased number of apoptotic cells upon CDDP + miR-29c treatment (increased 3.45 times; miR-29c vs. miR-NC: $76.3 \pm 14.3$ vs. 22.1 \pm 6.2 ) (Fig. 3D and E). These results indicated that overexpression of miR-29c may sensitize CDDP-resistant liver cancer to CDDP in vivo.

miR-29c directly targets SIRT1 to enhance CDDP sensitivity of liver cancer. To investigate the possible mechanisms by which miR-29c restores liver cancer sensitivity to CDDP, bioinformatics-based prediction was performed using TargetScan and miRDB (http://mirdb.org), and it was demonstrated that miR-29c may potentially target the SIRT1 3'-UTR. To 
A

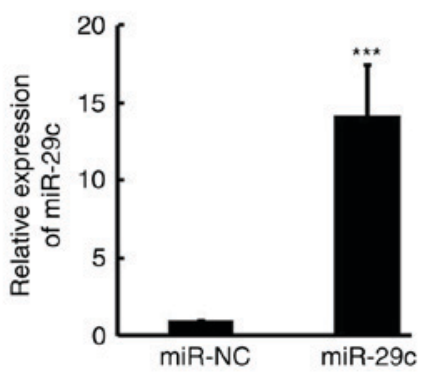

C

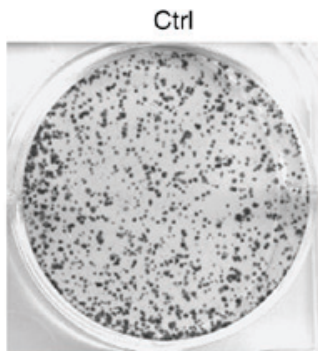

$\mathrm{E}$

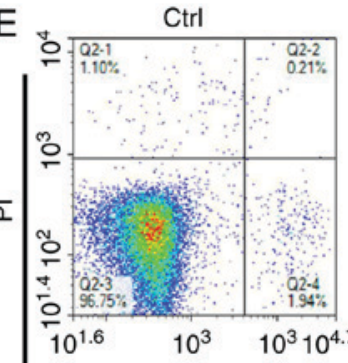

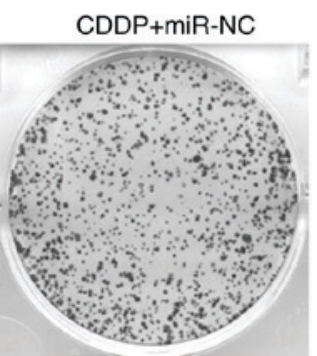

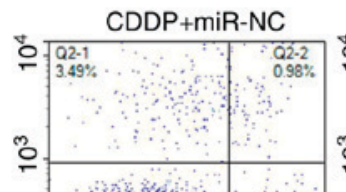

B

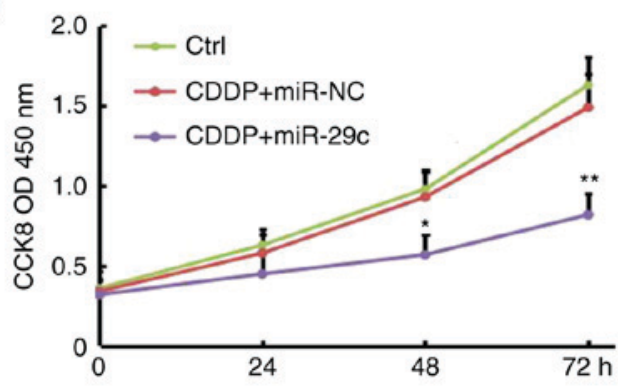

Annexin V-FITC
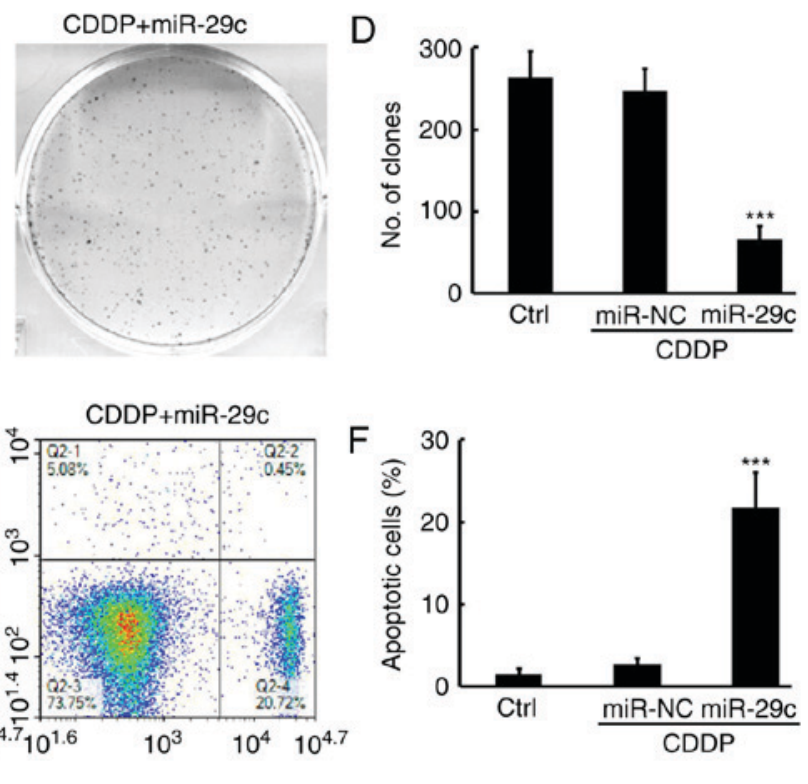

Figure 2. Overexpression of miR-29c restores CDDP sensitivity in liver cancer cells in vitro. (A) Overexpression of miR-29c in CDDP-R cells by quantitative polymerase chain reaction following transfection of miR-29c plasmid compared with miR-NC $(\mathrm{n}=3)$. (B) Overexpression of miR-29c and CDDP $(20 \mu \mathrm{M})$ treatment inhibited cell proliferate compared with that of CDDP $(20 \mu \mathrm{M})+$ miR-NC and non-treated control (Ctrl) in CDDP-R cells ( $\mathrm{n}=3)$. "P<0.05 and ${ }^{* *} \mathrm{P}<0.01$ vs sthe CDDP+miR-NC group. (C) Crystal violet staining of colony formation for CDDP $(20 \mu \mathrm{M})$ plus miR-NC or miR-29c combination treatments or non-treated control in CDDP-R cells after 10 days, with (D) statistical analysis of colony numbers for triplicate experiments (D) (n=3). (E) Flow cytometry analysis of apoptotic cells for CDDP $(20 \mu \mathrm{M})$ plus miR-NC or miR-29c combination treatments or non-treated control in CDDP-R cells after $48 \mathrm{~h}$, with (F) statistical analysis of apoptosis cells for triplicate experiments $(\mathrm{n}=3) .{ }^{* *} \mathrm{P}<0.01$ and ${ }^{* * * *} \mathrm{P}<0.001$ vs. the miR-NC group. NC, negative control; CCK8, Cell Counting Kit-8; OD, optical density; Ctrl, non-treated control; CDDP, cisplatin; PR, propidium iodide; FITC, fluorescein isothiocyanate; miR, microRNA.

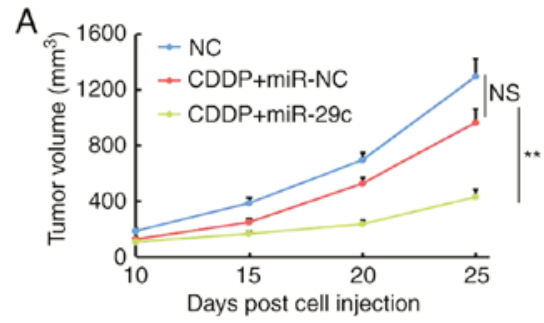

D

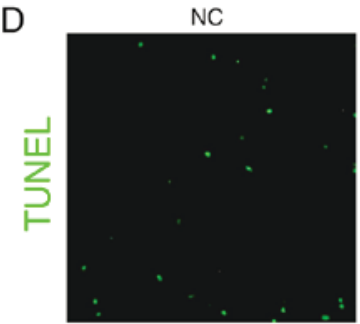

B

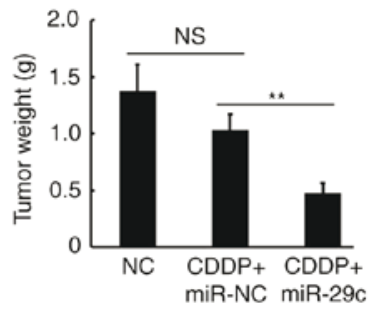

CDDP+miR-NC

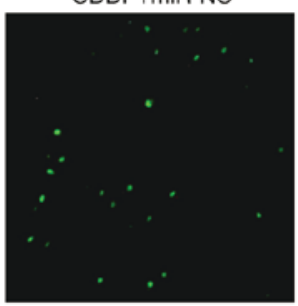

CDDP+miR-29c

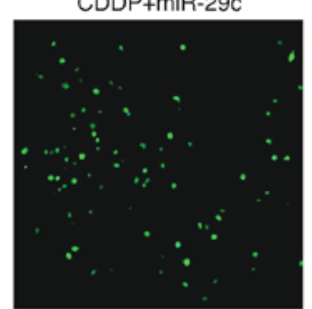

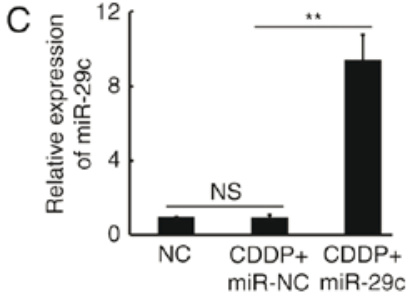

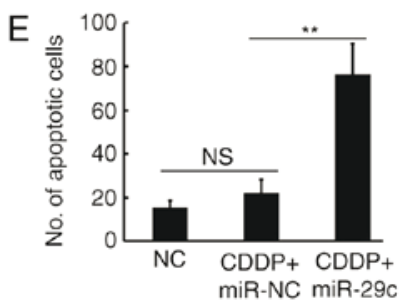

Figure 3. Overexpression of miR-29c restores CDDP sensitivity in liver cancer in vivo. (A) Tumor volume of xenograft tumors in nude mice measured every 5 days for a total of 25 days $(\mathrm{n}=4)$. Solvent or CDDP $(20 \mathrm{nmol})$ was injected every 3 days. (B) Tumor weight of xenograft tumors after sacrifice $(\mathrm{n}=5)$. (C) miR-29c expression was upregulated in CDDP + miR29c-treated tumors by quantitative polymerase chain reaction compared with that in the CDDP + miR-NC or Solvent group (n=4). (D) TUNEL analysis of apoptosis cells for Solvent, CDDP + miR-NC or CDDP + miR-29c-treated tumor sections, with (E) statistical analysis of apoptotic cells $(n=4){ }^{* *} \mathrm{P}<0.01$. Solvent, normal saline; NC, negative control; CDDP, cisplatin; miR, microRNA; NS, not significant. 
A

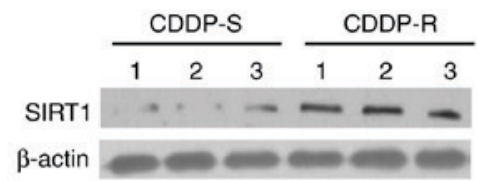

C

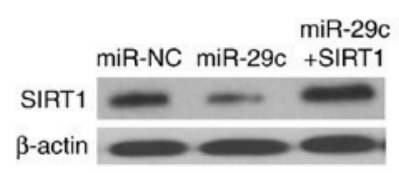

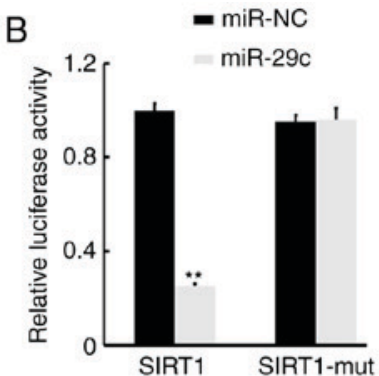

D $\rightarrow$ CDDP+miR-NC

$$
\rightarrow \text { CDDP+miR-29C }
$$

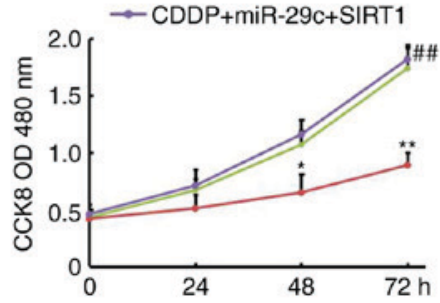

E

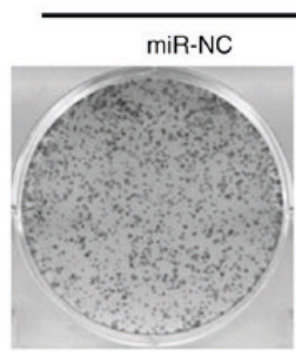

G
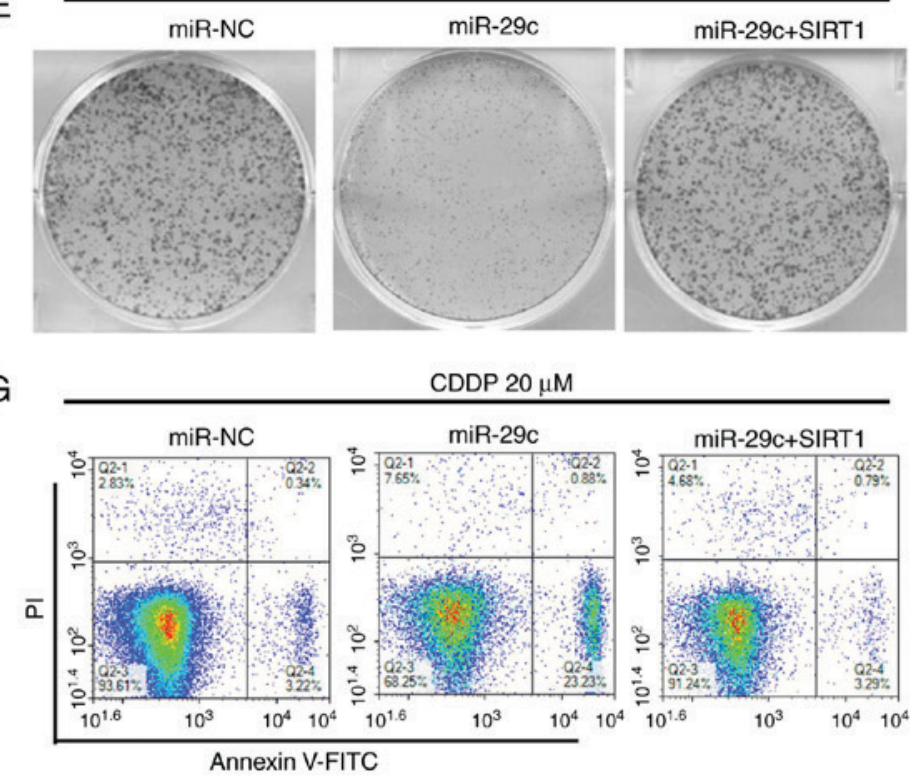

$\operatorname{CDDP} 20 \mu \mathrm{M}$
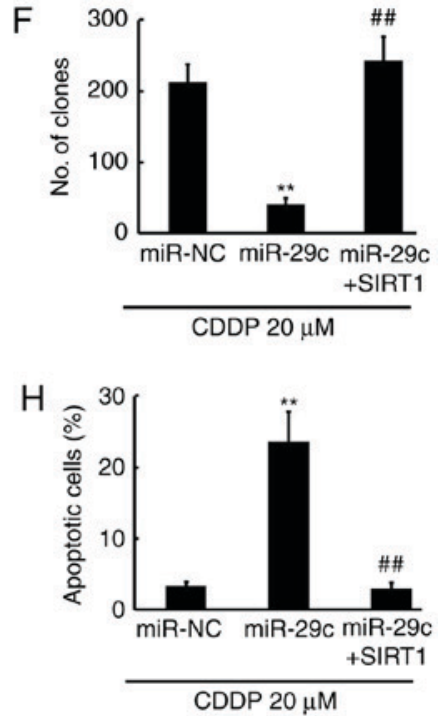

Figure 4. miR-29c directly targets SIRT1 to enhance CDDP sensitivity. (A) SIRT1 expression was upregulated in CDDP-R cells compared with that in CDDP-S cells for triplicate samples. $\beta$-actin was used as a loading control. The relative expression of SIRT1 was quantified. (B) Relative repression of luciferase expression was standardized to a transfection control. ${ }^{* *} \mathrm{P}<0.01$ vs. miR-NC. (C) SIRT1 was downregulated by miR-29c and restored by co-transfection of SIRT1 in CDDP-R cells. The relative expression of SIRT1 was quantified. (D) miR-29c + CDDP $(20 \mu \mathrm{M})$ treatment inhibited cell proliferation compared with CDDP $(20 \mu \mathrm{M})+$ miR-NC treatment, and overexpression of SIRT1 restored the cell proliferation compared with CDDP + miR-29c in CDDP-R cells $(\mathrm{n}=3)$. (E) Crystal violet staining of colony formation for CDDP $(20 \mu \mathrm{M})$ plus miR-NC or miR-29c combination treatments or SIRT1 in CDDP-R cells after 10 days as indicated, with (F) statistical analysis of colony numbers for triplicate experiments $(\mathrm{n}=3)$. (G) Flow cytometric analysis of apoptosis cells for CDDP $(20 \mu \mathrm{M})$ plus miR-NC or miR-29c combination treatments or SIRT1 in CDDP-R cells after $48 \mathrm{~h}$ as indicated, with (H) statistical analysis of apoptotic cells for triplicate experiments $(\mathrm{n}=3) .{ }^{* *} \mathrm{P}<0.01$ (vs. CDDP + miR-NC), ${ }^{\# \# /} \mathrm{P}<0.01$ (vs. CDDP + miR29c). CDDP, cisplatin; S, sensitive; R, resistant; SIRT1, silent mating type information regulation 2 homolog 1; NC, negative control run on the same membranes as the other proteins; FITC, fluorescein isothiocyanate; miR, microRNA; OD, optical density.

investigate if this was a possible mechanism for miR-29c-mediated restoration of liver cancer sensitivity to CDDP, the protein level of SIRT1 was determined and substantially increased SIRT1 protein levels were observed upon acquisition of CDDP resistance (Fig. 4A). A luciferase assay indicated that luciferase expression in SIRT1-3'UTR constructs was significantly affected by miR-29c, whereas no significant reduction was observed in SIRT1-3'UTR mutant constructs (Fig. 4B). A SIRT1 expression vector was ectopically expressed and verified that SIRT1 levels were restored (Fig. 4C). The present study assayed for cell viability and colony formation ability and identified that overexpression of SIRT1 relieves the effect of miR-29c on cell proliferation (CDDP + miR-NC, 1.74 $\pm 0,18$; CDDP + miR-29c, 0.89 $\pm 0.11 ;$ CDDP + miR-29c + SIRT1, $1.82 \pm 0.13)$ and colony numbers (CDDP + miR-NC, 213 \pm 25 ; CDDP + miR-29c, 42 \pm ; CDDP + miR-29c + SIRT1, 243 \pm 34$)$ (Fig. 4D-F). Additionally, overexpression of SIRT1 restores the effect of miR-29c, which promotes apoptosis in CDDP-R 
cell lines (CDDP + miR-NC, 3.38 $\pm 0.62 \%$; CDDP + miR-29c, $23.52 \pm 4.21 \%$; CDDP+miR-29c+SIRT1，3.04 $40.76 \%)$ (Fig. 4G-H). Collectively, these findings revealed that miR-29c can target and suppress SIRT1, and restore sensitivity to CDDP in CDDP-R liver cancer cell lines.

\section{Discussion}

Previous studies have indicated that miRNAs serve a crucial role in human cancer development $(7,26)$, with expression profiling of miRNAs being utilized for the classification of tumor stages and prognoses $(27,28)$. In the present study, miRNA expression patterns of liver cancer were screened and miR-29c was identified to be associated with chemoresistance. Further analysis demonstrated that miR-29c expression was downregulated in CDDP-R liver cancer cell lines and tissues compared with that in their CDDP-S counterparts.

The members of the miR-29 family function as tumor suppressors and are downregulated in several human cancers, including colon, lung, prostate, and breast cancer (29-32). The family includes miR-29a, miR-29b and miR-29c, which differ in their last few 3'-end nucleotides. Earlier studies have demonstrated that miR-29c acts as a tumor suppressor in gallbladder cancer by modulating levels of cell cycle regulator proteins (33).

The average miRNA has $~ 100$ target sites and regulates a large fraction of protein-coding genes (34). miR-29c, which inhibits cell proliferation, promotes apoptosis and arrests cell cycle at G1/G0 phase by targeting the Nuclear autoantigenic sperm protein, is downregulated in gastric cancer tissues and cell lines (20). miR-29c inhibits proliferation, migration and invasion in lung cancer cell lines by targeting vascular endothelial growth factor A in vitro (35). The present study provides evidence that miR-29c downregulates SIRT1 by targeting the 3'-UTR of SIRT1 mRNA. Using a series of in vitro and in vivo assays of liver cancer, cancer cell growth and colony formation were demonstrated to be significantly decreased by overexpression of miR-29c, whereas apoptosis was significantly increased, suggesting that it serves roles in chemoresistant cell proliferation, apoptosis and tumor growth. The antiproliferative effect of miR-29c overexpression appears to be associated with a change in SIRT1 expression level in chemoresistant cells over time.

Previous studies demonstrated that SIRT1 expression levels were positively correlated with tumor grade (36). Depletion of SIRT1 reduced the colony formation ability of liver cancer cells on soft agar, and xenograft growth in mice $(14,37)$. Furthermore, patients with SIRT1-positive liver cancer have a lower survival rate than those with SIRT1-negative liver cancer (38). Overexpression of SIRT1 has been demonstrated to contribute to chemoresistance in serous epithelial ovarian cancer, where it may be a potential prognostic indicator for patient survival outcome (39). SIRT1 is one among other genes involved in DNA repair that are upregulated in platinum-resistant epithelial ovarian cancer (40).

Collectively, data from the present and previous studies support a pro-tumorigenic and chemoresistant role for SIRT1, which may be targeted by miR-29c in liver cancer. As an miRNA may inhibit more than one target gene, a single gene could be targeted by multiple miRNAs, the results of the present study demonstrate only one point of the regulating network that could impact liver tumor progression.

\section{Acknowledgements}

Not applicable.

\section{Funding}

No funding was received.

\section{Availability of data and materials}

All data generated or analyzed during this study are included in this published article.

\section{Author's contributions}

PL was involved in the acquisition of the data and the analysis and interpretation of the data. WZ was involved in the conception and design of the present study.

\section{Ethics approval and consent to participate}

Procedures involving animals conformed to the guidelines of the Institutional Animal Care and Use Committee of Sichuan Academy of Medical Sciences and Sichuan Provincial People's Hospital (Sichuan, China).

\section{Consent for publication}

Not applicable.

\section{Competing interests}

The authors declare that they have no competing interests.

\section{References}

1. Islami F, Miller KD, Siegel RL, Fedewa SA, Ward EM and Jemal A: Disparities in liver cancer occurrence in the United States by race/ethnicity and state. CA Cancer J Clin 67: 273-289, 2017.

2. Chen W, Zheng R, Baade PD, Zhang S, Zeng H, Bray F, Jemal A, Yu XQ and He J: Cancer statistics in China, 2015. CA Cancer J Clin 66: 115-132, 2016.

3. Herold C, Reck T, Fischler P, Ott R, Radespiel-Troeger M, Ganslmayer M, Hohenberger W, Hahn EG and Schuppan D: Prognosis of a large cohort of patients with hepatocellular carcinoma in a single European centre. Liver 22: 23-28, 2002.

4. Xiong H, Ni Z, He J, Jiang S, Li X, He J, Gong W, Zheng L, Chen S, Li B, et al: LncRNA HULC triggers autophagy via stabilizing Sirt1 and attenuates the chemosensitivity of HCC cells. Oncogene 36: 3528-3540, 2017.

5. Zhang H, Feng Z, Huang R, Xia Z, Xiang G and Zhang J: MicroRNA-449 suppresses proliferation of hepatoma cell lines through blockade lipid metabolic pathway related to SIRT1. Int J Oncol 45: 2143-2152, 2014.

6. Bhalla KN: Epigenetic and chromatin modifiers as targeted therapy of hematologic malignancies. J Clin Oncol 23: 3971-3993, 2005.

7. Bertoli G, Cava C and Castiglioni I: MicroRNAs: New biomarkers for diagnosis, prognosis, therapy prediction and therapeutic tools for breast cancer. Theranostics 5: 1122-1143, 2015.

8. Brennecke J, Hipfner DR, Stark A, Russell RB and Cohen SM: Bantam encodes a developmentally regulated microRNA that controls cell proliferation and regulates the proapoptotic gene hid in drosophila. Cell 113: 25-36, 2003. 
9. Hatfield SD, Shcherbata HR, Fischer KA, Nakahara K, Carthew RW and Ruohola-Baker H: Stem cell division is regulated by the microRNA pathway. Nature 435: 974-978, 2005.

10. Pekarsky Y, Santanam U, Cimmino A, Palamarchuk A, Efanov A, Maximov V, Volinia S, Alder H, Liu CG, Rassenti L, et al: Tcll expression in chronic lymphocytic leukemia is regulated by miR-29 and miR-181. Cancer Res 66: 11590-11593, 2006.

11. Fang F, Chang RM, Yu L, Lei X, Xiao S, Yang H and Yang LY: MicroRNA-188-5p suppresses tumor cell proliferation and metastasis by directly targeting FGF5 in hepatocellular carcinoma. J Hepatol 63: 874-885, 2015.

12. Firestein R, Blander G, Michan S, Oberdoerffer P, Ogino S, Campbell J, Bhimavarapu A, Luikenhuis S, de Cabo R Fuchs C, et al: The SIRT1 deacetylase suppresses intestinal tumorigenesis and colon cancer growth. PLoS One 3: e2020, 2008.

13. Guarente L: Calorie restriction and sirtuins revisited. Genes Dev 27: 2072-2085, 2013.

14. Chen J, Zhang B, Wong N, Lo AW, To KF, Chan AW, Ng MH, Ho CY, Cheng SH, Lai PB, et al: Sirtuin 1 is upregulated in a subset of hepatocellular carcinomas where it is essential for telomere maintenance and tumor cell growth. Cancer Res 71: 4138-4149, 2011.

15. Portmann S, Fahrner R, Lechleiter A, Keogh A, Overney S, Laemmle A, Mikami K, Montani M, Tschan MP, Candinas D and Stroka D: Antitumor effect of SIRT1 inhibition in human HCC tumor models in vitro and in vivo. Mol Cancer Ther 12: 499-508, 2013

16. Dong CW, Wang YX, Du FT, Ding W and Hu SY: Low miR-29c expression is a prognostic marker in hepatocellular carcinoma. Genet Mol Res 15: 2016.

17. Lu Y, Hu J, Sun W, Li S, Deng S and Li M: MiR-29c inhibits cell growth, invasion, and migration of pancreatic cancer by targeting ITGB1. Onco Targets Ther 9: 99-109, 2015.

18. Zhao X, Li J, Huang S, Wan X, Luo H and Wu D: MiRNA-29c regulates cell growth and invasion by targeting CDK6 in bladder cancer. Am J Transl Res 7: 1382-1389, 2015.

19. Wang B, Li D, Sidler C, Rodriguez-Juarez R, Singh N, Heyns M, Ilnytskyy Y, Bronson RT and Kovalchuk O: A suppressive role of ionizing radiation-responsive miR-29c in the development of liver carcinoma via targeting WIP1. Oncotarget 6: 9937-9950, 2015.

20. Yu B, Chen X, Li J, Gu Q, Zhu Z, Li C, Su L and Liu B: microRNA-29c inhibits cell proliferation by targeting NASP in human gastric cancer. BMC Cancer 17: 109, 2017.

21. Lopez-Terrada D, Cheung SW, Finegold MJ and Knowles BB: Hep G2 is a hepatoblastoma-derived cell line. Hum Pathol 40: $1512-1515,2009$.

22. Luo P, He T, Jiang R and Li G: MicroRNA-423-5p targets O-GlcNAc transferase to induce apoptosis in cardiomyocytes. Mol Med Rep 12: 1163-1168, 2015.

23. Cheng L, Yang Q, Li C, Dai L, Yang Y, Wang Q, Ding Y, Zhang J, Liu L, Zhang S, et al: DDA1, a novel oncogene, promotes lung cancer progression through regulation of cell cycle. J Cell Mol Med 21: 1532-1544, 2017.

24. Livak KJ and Schmittgen TD: Analysis of relative gene expression data using real-time quantitative PCR and the 2(-Delta Delta C(T)) method. Methods 25: 402-408, 2001.

25. Dai L, Cui X, Zhang X, Cheng L, Liu Y, Yang Y, Fan P, Wang Q, Lin Y, Zhang J, et al: SARI inhibits angiogenesis and tumour growth of human colon cancer through directly targeting ceruloplasmin. Nat Commun 7: 11996, 2016.
26. Chang Y, Liu C, Yang J, Liu G, Feng F, Tang J, Hu L, Li L, Jiang F, Chen C, et al: MiR-20a triggers metastasis of gallbladder carcinoma. J Hepatol 59: 518-527, 2013.

27. Yang X, Zhang XF, Lu X, Jia HL, Liang L, Dong QZ, Ye QH and Qin LX: MicroRNA-26a suppresses angiogenesis in human hepatocellular carcinoma by targeting hepatocyte growth factor-cMet pathway. Hepatology 59: 1874-1885, 2014.

28. Altman DG, McShane LM, Sauerbrei W and Taube SE: Reporting recommendations for tumor marker prognostic studies (REMARK): Explanation and elaboration. PLoS Med 9: e1001216, 2012.

29. Cummins JM, He Y, Leary RJ, Pagliarini R, Diaz LA Jr, Sjoblom T, Barad O, Bentwich Z, Szafranska AE, Labourier E, et al: The colorectal microRNAome. Proc Natl Acad Sci USA 103: 3687-3692, 2006.

30. Fabbri M, Garzon R, Cimmino A, Liu Z, Zanesi N, Callegari E, Liu S, Alder H, Costinean S, Fernandez-Cymering C, et al: MicroRNA-29 family reverts aberrant methylation in lung cancer by targeting DNA methyltransferases 3A and 3B. Proc Natl Acad Sci USA 104: 15805-15810, 2007.

31. Porkka KP, Pfeiffer MJ, Waltering KK, Vessella RL, Tammela TL and Visakorpi T: MicroRNA expression profiling in prostate cancer. Cancer Res 67: 6130-6135, 2007.

32. Iorio MV, Ferracin M, Liu CG, Veronese A, Spizzo R, Sabbioni S, Magri E, Pedriali M, Fabbri M, Campiglio M, et al: MicroRNA gene expression deregulation in human breast cancer. Cancer Res 65: 7065-7070, 2005.

33. Pang L, Gu W, Wang N, Hu J, Cui X, Zhang J, Zhao J, Liu C, Zhang W, Zou H, et al: MicroRNA-29c-5p suppresses gallbladder carcinoma progression by directly targeting CPEB4 and inhibiting the MAPK pathway. Clin Exp Pharmacol Physiol 24: 445-457, 2017 (In Chinese).

34. Brennecke J, Stark A, Russell RB and Cohen SM: Principles of microRNA-target recognition. PLoS Biol 3: e85, 2005.

35. Liu L, Bi N, Wu L, Ding X, Men Y, Zhou W, Li L, Zhang W, Shi S, Song Y and Wang L: MicroRNA-29c functions as a tumor suppressor by targeting VEGFA in lung adenocarcinoma. Mol Cancer 16: 50, 2017.

36. Chen HC, Jeng YM, Yuan RH, Hsu HC and Chen YL: SIRT1 promotes tumorigenesis and resistance to chemotherapy in hepatocellular carcinoma and its expression predicts poor prognosis. Ann Surg Oncol 19: 2011-2019, 2012.

37. Wu Y, Meng X, Huang C and Li J: Emerging role of silent information regulator 1 (SIRT1) in hepatocellular carcinoma: A potential therapeutic target. Tumour Biol 36: 4063-4074, 2015.

38. Choi HN, Bae JS, Jamiyandorj U, Noh SJ, Park HS, Jang KY, Chung MJ, Kang MJ, Lee DG and Moon WS: Expression and role of SIRT1 in hepatocellular carcinoma. Oncol Rep 26: 503-510, 2011.

39. Shuang T, Wang M, Zhou Y and Shi C: Over-expression of Sirt1 contributes to chemoresistance and indicates poor prognosis in serous epithelial ovarian cancer (EOC). Med Oncol 32: 260, 2015.

40. Ziebarth AJ, Nowsheen S, Steg AD, Shah MM, Katre AA, Dobbin ZC, Han HD, Lopez-Berestein G, Sood AK, Conner M, et al: Endoglin (CD105) contributes to platinum resistance and is a target for tumor-specific therapy in epithelial ovarian cancer. Clin Cancer Res 19: 170-182, 2013.

This work is licensed under a Creative Commons Attribution-NonCommercial-NoDerivatives 4.0 International (CC BY-NC-ND 4.0) License. 